\title{
Tree phenology and carbon dioxide fluxes: use of digital photography for process-based interpretation at the ecosystem scale
}

\author{
H. E. Ahrends ${ }^{1,2, *}$, S. Etzold ${ }^{2}$, W. L. Kutsch ${ }^{3}$, R. Stoeckli ${ }^{4}$, R. Bruegger ${ }^{1}$, F. Jeanneret ${ }^{1}$, \\ H. Wanner ${ }^{1}$, N. Buchmann ${ }^{2}$, W. Eugster ${ }^{2}$ \\ ${ }^{1}$ Institute of Geography, University of Bern, Hallerstrasse 12, 3012 Bern, Switzerland \\ ${ }^{2}$ Institute of Plant Sciences, ETH Zurich, Universitaetsstrasse 2, 8092 Zurich, Switzerland \\ ${ }^{3}$ Max-Planck-Institute for Biogeochemistry, Hans-Knoell-Strasse 10, 07745 Jena, Germany \\ ${ }^{4}$ Federal Office of Meteorology and Climatology MeteoSwiss, Climate Services, Climate Analysis, Kraehbuehlstrasse 58, \\ 8044 Zurich, Switzerland
}

\begin{abstract}
Vegetation phenology is an important indicator of climate change and climate variability and it is strongly connected to biospheric-atmospheric gas exchange. We aimed to evaluate the applicability of phenological information derived from digital imagery for the interpretation of $\mathrm{CO}_{2}$ exchange measurements. For the years 2005-2007 we analyzed seasonal phenological development of 2 temperate mixed forests using tower-based imagery from standard RGB cameras. Phenological information was jointly analyzed with gross primary productivity (GPP) derived from net ecosystem exchange data. Automated image analysis provided reliable information on vegetation developmental stages of beech and ash trees covering all seasons. A phenological index derived from image color values was strongly correlated with GPP, with a significant mean time lag of several days for ash trees and several weeks for beech trees in early summer (May to mid-July). Leaf emergence dates for the dominant tree species partly explained temporal behaviour of spring GPP but were also masked by local meteorological conditions. We conclude that digital cameras at flux measurement sites not only provide an objective measure of the physiological state of a forest canopy at high temporal and spatial resolutions, but also complement $\mathrm{CO}_{2}$ and water exchange measurements, improving our knowledge of ecosystem processes.
\end{abstract}

KEY WORDS: Phenology · Growing season - Digital camera - Image analysis · Gross primary productivity · Forest

Resale or republication not permitted without written consent of the publisher

\section{INTRODUCTION}

Variations in plant phenology affect the timing, phase and magnitude of the net ecosystem exchange (NEE) of $\mathrm{CO}_{2}$ between the biosphere and the atmosphere. As a consequence the terrestrial carbon and water cycle, as well as the atmospheric $\mathrm{CO}_{2}$ concentration, strongly depend on the timing of plant phenological phases (Keeling et al. 1996, Fitzjarrald et al. 2001, Peñuelas \& Filella 2001, Obrist et al. 2003).

Within the course of the year, springtime seems to exert the strongest control over the annual carbon bud- get of ecosystems (Goulden et al. 1996, Berninger 1997, Black et al. 2000, Barr et al. 2007, Richardson et al. 2009a). Earlier leaf development results in a pronounced carbon gain in spring (Morecroft et al. 2003, Niemand et al. 2005). In contrast, the length of the growing season appears to be less important for the annual carbon budget, probably due to a concurrent increase in ecosystem respiration (White \& Nemani 2003, Dunn et al. 2007). It is even likely that carbon gain in spring due to earlier green-up can be offset by carbon losses in autumn (Piao et al. 2008). Consequently, the variation in other environmental factors 
such as precipitation and temperature has to be included as a potential driving factor in order to evaluate the impacts of interannual variation in phenology on annual budgets of gas and water exchange (Nemani et al. 2002, Piao et al. 2007).

In order to better constrain the global carbon cycle in model simulations, budburst and leaf senescence need to be represented more accurately in these models (Chiang \& Brown 2007). This, however, still remains a challenging task since often simple empirical models are used to track phenological phases in land-surface models, for instance based on growing degree-days, onset and offset of the carbon uptake period (Baldocchi et al. 2005, Delpierre et al. 2009b) or carbon gain-based schemes (Arora \& Boer 2005). The magnitude of the response of forest primary productivity varies with the phenological model applied (Leinonen \& Kramer 2002).

Extensive efforts in the last few years have lead to an increased number of standardized phenological networks and databases (van Vliet et al. 2003, Betancourt et al. 2005). Nevertheless, the availability of phenological field observations is still restricted with respect to temporal and spatial resolution, and observations are prone to subjectivity according to the specific conditions and skills of the observer (Menzel 2002, Schwartz et al. 2006). For global up-scaling and detection of spatial patterns in climate change impacts, spectral reflectance of the earth's surface obtained from satellite measurements is typically used. In phenology research, satellite data are also used, such as from NOAA Advanced Very High Resolution Radiometer (AVHRR), Moderate Resolution Imaging Spectroradiometer (MODIS) or Spot VEGETATION. However, the temporal resolution and the quality of satellite observations are limited due to clouds, snow cover and atmospheric disturbances (Ahl et al. 2006, Zhang et al. 2006). Furthermore, sensor characteristics limit the spatial resolution (range: 250 to $1000 \mathrm{~m}$ ). Thus there is still a critical need for precise field data for understanding and validating satellite data (Studer et al. 2007). Most important in this context is the large gap between spatially integrated information from satellite sensors that do not distinguish among individual tree species and point observations of phenological events at the species level (Schwartz \& Reed 1999, Linderholm 2006).

Although recent studies have demonstrated the suitability of digital camera images for spring phenological monitoring in ecosystem studies (Richardson et al. 2007, 2009a, Ahrends et al. 2008), the direct linkage between such observations and quantitative $\mathrm{CO}_{2}$ measurements has not yet been achieved. The objective of the present study was to evaluate whether digital images from standard RGB cameras can be of use for the interpretation of seasonal changes in carbon flux measurements. Digital images from 2 different forests in central Germany and northern Switzerland were used to derive phenological dates for 2 dominant forest tree species (beech and ash) for each season during the years 2005 to 2007. Phenological data were then combined with gross primary productivity (GPP) in order to increase our ecosystem-scale understanding of the seasonal covariation between GPP and tree phenology. The key questions to be answered were: (1) Are phenological dates of dominant tree species crucial for carbon dioxide fluxes in forests? (2) Can phenological dates be related to GPP? (3) Are there significant time lags in spring and early summer between the productivity of a forest and the phenological dates, due to delayed physiological acclimatization of the trees?

\section{MATERIALS AND METHODS}

\subsection{Research sites}

The Lägeren Forest is a managed mixed forest located in northern Switzerland. The digital camera is installed on the upper platform of a tower $45 \mathrm{~m}$ high, situated at $47^{\circ} 28^{\prime} 49^{\prime \prime} \mathrm{N}$ and $8^{\circ} 21^{\prime} 05^{\prime \prime} \mathrm{E}$ at $682 \mathrm{~m}$ above sea level (a.s.l.; base of tower) on the steep (on average $24^{\circ}$ ), south-facing slope of the Lägeren mountain (866 $\mathrm{m}$ a.s.l.). Routine $\mathrm{CO}_{2}$ and $\mathrm{H}_{2} \mathrm{O}$ flux measurements as a contribution to the FLUXNET/ CarboEuropeIP network started at the Lägeren research site in April 2004. Beech trees Fagus sylvatica contribute $25 \%$ of the aboveground stem volume in the fetch-area of eddy covariance measurements, ash trees Fraxinus excelsior $17 \%$, sycamore Acer pseudoplatanus 15\% and coniferous trees (Picea abies, Abies alba) 32\% (Eugster et al. 2007). In spring the understory vegetation is dominated by bear's garlic Allium ursinum. In general, the partly managed forest stand has a relatively high diversity of species and there is significant variation in age and diameter distribution (Eugster et al. 2007). The mean annual temperature is $8.3^{\circ} \mathrm{C}$ and the mean annual precipitation is $1100 \mathrm{~mm}$.

The Hainich Forest is an unmanaged deciduous forest located in central Germany in the Thuringian Basin $\left(51^{\circ} 04^{\prime} 45^{\prime \prime} \mathrm{N}, 10^{\circ} 27^{\prime} 07^{\prime \prime} \mathrm{E}, 440 \mathrm{~m}\right.$ a.s.l). It covers an area of about 7600 ha (Knohl \& Baldocchi 2008). Ecosystem net carbon and water vapour fluxes have been measured continuously with an eddy covariance system from a tower $43.5 \mathrm{~m}$ high since October 1999 (FLUXNET/ CarboEurope IP network). The tower is located on a north-facing slope with less than $2^{\circ}$ inclination around the tower. The Hainich Forest has a high diversity of species and age classes. Since large parts of the forest have remained unmanaged for decades, the canopy is vertically structured and it maintains large dead wood pools and canopy gaps (Knohl \& Baldocchi 2008). The forest is 
dominated by beech (65\%) and co-dominated by ash (25\%) and sycamore Acer pseudoplatanus and A. plantanoides $(7 \%)$. Ground vegetation includes Allium ursinum, Mercurialis perennis and Anemone nemorosa. The mean annual temperature is $7.5^{\circ} \mathrm{C}$ and the mean annual precipitation is 750 to $800 \mathrm{~mm}$. For detailed site characteristics see Knohl et al. (2003).

\subsection{Derivation of $\mathrm{CO}_{2}$ fluxes and data processing}

Techniques for measuring and estimating $\mathrm{CO}_{2}$ fluxes and data processing procedures were optimized for each site separately to achieve the best possible flux representation.

At the Lägeren site, a 3D ultrasonic anemometer (model 1199 HSE with a built-in inclinometer, Gill Instruments) and an open-path infrared gas analyser (LiCor 7500, LiCor) were installed at a height of $45 \mathrm{~m}$ to measure NEE using the eddy covariance technique (Baldocchi 2003); 30 min averages of $\mathrm{CO}_{2}$ and water vapour fluxes were calculated offline from digitally collected eddy co-variance (EC) raw data by the in-house software ethflux. Within this program, coordinate rotation is done by 2D-rotation (McMillen 1988), as the planar fit method was identified to be not suitable for the Lägeren site (Göckede et al. 2008). Quality checks of the data were performed by the standard procedure of the CarboEurope network (Papale et al. 2006). More details about the EC data processing are given in Hiller et al. (2008). The $30 \mathrm{~min} \mathrm{CO}_{2}$ flux averages were corrected for the change of $\mathrm{CO}_{2}$ storage below the measuring height of the EC instrumentation, derived from a vertical $\mathrm{CO}_{2}$ profile at 8 heights. Gap filling of NEE data was performed using the method described in Reichstein et al. (2005). Data were accepted and used for gap-filling if they met all of the following criteria:

(1) window dirtiness (housekeeping variable provided by the Li-7500 open-path instrument) $<60 \%$;

(2) $\mathrm{CO}_{2}$ concentration 11 to $20 \mathrm{mmol} \mathrm{m}^{-3}$;

(3) $\mathrm{CO}_{2}$ flux -50 to $50 \mu \mathrm{mol} \mathrm{m} \mathrm{m}^{-2} \mathrm{~s}^{-1}$;

(4) change of $\mathrm{CO}_{2}$ storage -30 to $30 \mu \mathrm{mol} \mathrm{m}{ }^{-2} \mathrm{~s}^{-1}$;

(5) momentum flux $\overline{\mathrm{u}^{\prime} \mathrm{w}^{\prime}}<0 \mathrm{~m}^{2} \mathrm{~s}^{-2}$ (Eugster et al. 2003, 2007);

(6) quality flag $\leq 1$ (Foken \& Wichura 1996) that reached a certain, site-specific and temperaturedependent friction velocity threshold $\left(\mathrm{u}^{*}=\sqrt{-\overline{\mathrm{u}^{\prime} \mathrm{w}^{\prime}}}\right)$ $\left.11 \mathrm{mmol} \mathrm{m}^{-3}<\right)\left(0.3 \mathrm{~m} \mathrm{~s}^{-1}\right)$.

After $\mathrm{u}^{*}$-filtering, accepted data covered $39.7 \%$ of all available data in 2005, 40.5\% in 2006 and $42.6 \%$ in 2007. The gap-filled Lägeren NEE data were partitioned into the 2 main contributing processes, GPP and total ecosystem respiration $\left(R_{e}\right.$, the sum of autotrophic and heterotrophic respiration), by using the method detailed in Reichstein et al. (2005).
At the Hainich site, eddy covariance flux measurements were performed at a height of $43.5 \mathrm{~m}$ since 1999, using a triaxial sonic anemometer (Gill Solent R3, Gill Instruments) and a fast response closed-path $\mathrm{CO}_{2} / \mathrm{H}_{2} \mathrm{O}$ infrared gas analyzer (LiCor 6262, LiCor). More details on data processing are given in Knohl et al. (2003). However, since nighttime fluxes of eddy covariance are severely biased by advection at the Hainich site, data based on an independent bottom-up modelling approach of the main ecosystem processes were used in the present study. The model modules were calibrated either with data from chamber measurements at the site or with literature values from other sites. Eddy covariance measurements were used only to calibrate each year separately with respect to the start and the end of the growing season. Module results were summed up to modelled NEE, GPP, and $R_{e}$. Details on the modelling approach are given in Kutsch et al. (2008).

\subsection{Camera images and image analysis}

\subsubsection{Technical setup}

Digital cameras were mounted on the uppermost platforms of the flux towers in weatherproof housings. At the Hainich site, a Kodak DC290 Zoom camera provided JPEG images (image resolution of 2.1 MP), and at the Lägeren site a Nikon Coolpix 5400 provided RAW images (5 MP). Both cameras were operated in the automatic aperture and exposure mode. Image capturing worked automatically based on site-specific software. Cameras provided hourly images (excluding the dark hours) at the Lägeren site and 1 image per day with capture time around local noon (ranging from 10:30 to $14: 30 \mathrm{~h}$ ) at the Hainich site. Hainich JPEG images were not processed. The RAW-images (NEFformat) from the Lägeren site were processed using Adobe Photoshop software. For each image, the same default settings with respect to tone, contrast and brightness and a linear gradation curve were applied. The white balance was used according to the camera settings. Images were then saved as TIFF (8 Bit). We used Adobe software on the basis of its ability to correct for manually adjusted brightness correction values of the camera.

Contrary to the setup at the Lägeren forest, the camera at the Hainich site was moved inadvertently, and hence its field of view (FOV) changed horizontally and vertically several times during the observation period. Thus different trees were covered by the FOV and the view angle varied by several degrees below the horizon. At the Lägeren site, the cameras' FOV was stable and the view angle was tilted $25^{\circ}$ below the horizon (Ahrends et al. 2008). 


\subsubsection{Image analysis}

Image analysis was done on a daily time step. We used the available daily imagery from the Hainich site and selected the images taken near local noon $(12: 30 \mathrm{~h})$ from the Lägeren site. Thus we minimized the influence of diurnal and seasonal changes in illumination geometry on image color values. Days with rain, snow and fog were manually excluded from the analysis. In total, 978 images from the Hainich site and 649 from the Lägeren site were used in the analyses of the years 2005, 2006 and 2007. The largest gap in the Lägeren imagery was in summer 2005 (DOY 171 to 243) and in the Hainich imagery in spring 2007 (DOY 133 to 165 ) due to technical failures.

Image analysis was conducted as described in Ahrends et al. (2008) on a set of regions of interest (ROIs) separately for beech and ash trees (Fig. 1). ROIs specified for the Hainich imagery were changed several times according to the changing FOV of the cam-

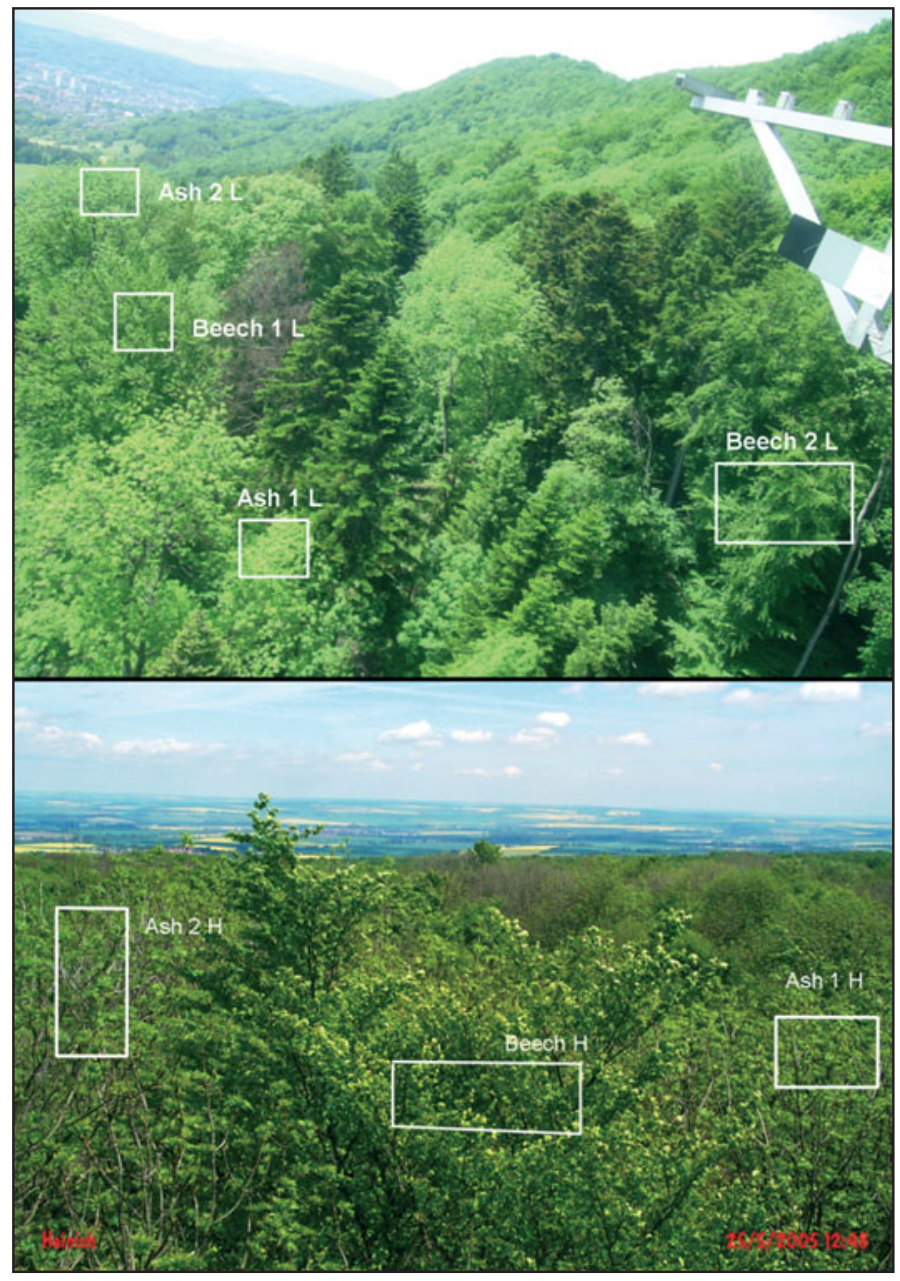

Fig. 1. Sample images and analyzed regions of interest (ROI). (a) Lägeren Forest (L), 24 May 2005; (b) Hainich Forest (H), 25 May 2005. Regions are named after the dominant tree species covered by the ROI era. ROIs therefore did not always match the same individual tree, but they did match species. The image's color (red, green and blue) values then were extracted and averaged across each ROI at daily intervals using interactive data language (IDL) software. The green fraction (GF, mean green raw value divided by the sum of mean green, red and blue raw values) was computed on a daily time step for each ROI in each year.

\subsection{Linking image color values to tree phenology}

The GF shows a pronounced seasonal course and thus can be used to derive a signal describing vegetation developmental stages (Richardson et al. 2007, Ahrends et al. 2008). Following the approach of Zhang et al. (2003), our objective was to estimate 3 different phenological dates commonly used in remote sensing studies: (1) start of the growing season (SOS): date of appearance of the first leaves, although not yet fully unfolded; (2) start of leaf senescence (SEN): the date when the first leaves of the beech trees become coloured due to chlorophyll destruction and nutrient resorption processes (in ash trees, leaf abscission was observed, since ash trees mostly shed their leaves green); and (3) end of the growing season (EOS): the date which describes the state of complete foliage loss.

Additionally, we calculated the day of year (DOY) of the maximum GF value $\left(\mathrm{GF}_{\max }\right)$ to describe the approximate date when leaf unfolding processes are finished. Although SOS, SEN and EOS are described as phenological dates in the present study, these dates do not equate with traditional phenological dates as observed in field studies.

We determined the different dates using piecewise first and second derivative analyses. First, data gaps in GF time series were linearly interpolated. The first and second derivatives were calculated and smoothed by use of a 10-window boxcar filter. The SOS of ROIs mainly covering beech trees was estimated by evaluating the maximum of the smoothed second derivative between a user-defined onset (DOY 30) and GF $_{\text {max }}$, which typically matches the date when all leaves are unfolded. Ash trees generally unfold their leaves later than beech trees; therefore, we used the SOS date of the ROIs covering beech trees as a lower time threshold to estimate the SOS date of ash trees. SEN was estimated backwards from the minimum of the first derivative between user-defined time thresholds (here we used DOY 200 and 340) to the first value that crosses zero (i.e. first derivative becomes positive). Starting from the minimum of the first derivative found in the previous step, the tree was found to be nearly leafless at the date when the first derivative equals zero and becomes positive (EOS). Foliage duration, defined as 
the number of days between leaf appearance and complete leaf fall, was approximated for each region using the time difference between EOS and SOS. Due to a technical failure, no images for spring 2007 were available for the Hainich site; therefore, SOS dates in 2007 are missing.

\subsection{Validation of image-based phenology}

To evaluate the performance of the method and to verify its ability to observe tree phenology, validation data are needed. Since independent field observations are only available to a limited extent, we used visual estimates based on imagery (Fisher et al. 2006, Sparks et al. 2006). Four independent observers analyzed all available imagery from spring and autumn. They classified the phenological development from bud break to fully developed canopy on a 0 to $100 \%$ scale. Accordingly, leaf senescence was classified from the beginning of visible leaf coloring (beech trees) and leaf fall (ash trees) to leafless canopy on a 0 to $100 \%$ scale, respectively. Trees that were covered by the same ROIs as used in automated image processing were observed. Visual estimates are seen as a general knowledge-based verification tool and cannot be taken for independent validation data.

\subsection{Linking image-derived information to $\mathrm{CO}_{2}$ data}

GF values were jointly analyzed with GPP, which describes the amount of carbon that is assimilated through photosynthesis, and thus describes photosynthesis at the ecosystem scale (Chapin et al. 2002).

Data analyses were performed using the statistical software package R (www.r-project.org/). We calculated the time series cross-correlation between GF values and GPP in each year and during different time periods of the year, seeking the time lag which gave the maximum cross-correlation. Positive time lags indicate that GF leads GPP, negative time lags that GF lags GPP. We fitted a linear least-squares regression model to the values between estimated SOS and $\mathrm{GF}_{\max }$ dates.

\section{RESULTS}

\subsection{Images and forest phenology}

\subsubsection{Verification of image-based data}

Generally, agreement between different independent observers strongly depended on tree species and phenological date. With respect to beech trees, SOS dates were similar, whereas $\mathrm{GF}_{\max }$, SEN and EOS strongly

Table 1. Phenological dates (day of year) derived from digital camera images (Cam) and mean dates from independent observers (Obs). ROI: region of interest; SOS: start of growing season; SEN: start of leaf senescence; EOS: end of growing season; Diff: absolute difference between Cam and Obs dates; FOL: foliage duration (EOS - SOS); B: beech; A: ash; NA: not available

\begin{tabular}{|c|c|c|c|c|c|c|c|c|c|c|c|}
\hline & \multirow{2}{*}{ ROI } & \multicolumn{3}{|c|}{$-\operatorname{SOS} \longleftarrow$} & \multicolumn{3}{|c|}{$\longrightarrow$ SEN- } & \multicolumn{3}{|c|}{- EOS } & \multirow{2}{*}{$\begin{array}{l}\text { FOL } \\
\text { Cam }\end{array}$} \\
\hline & & Cam & Obs & Diff & Cam & Obs & Diff & Cam & Obs & Diff & \\
\hline \multicolumn{12}{|c|}{ Lägeren } \\
\hline \multirow[t]{4}{*}{2005} & B1 & 115 & 121 & 6 & 263 & 264 & 1 & 306 & 293 & 13 & 191 \\
\hline & B2 & 115 & 120 & 5 & 278 & 280 & 2 & 334 & 308 & 26 & 219 \\
\hline & A1 & 133 & 132 & 1 & 279 & 285 & 6 & 311 & 304 & 7 & 178 \\
\hline & A2 & 137 & NA & NA & 271 & NA & NA & 308 & NA & NA & 171 \\
\hline \multirow[t]{4}{*}{2006} & B1 & 116 & 117 & 1 & 257 & 260 & 3 & 309 & 297 & 12 & 193 \\
\hline & B2 & 116 & 115 & 1 & 309 & 276 & 33 & 326 & 316 & 10 & 210 \\
\hline & $\mathrm{A} 1$ & 130 & 124 & 6 & 275 & 280 & 5 & 309 & 304 & 5 & 179 \\
\hline & $\mathrm{A} 2$ & 123 & NA & NA & 275 & NA & NA & 288 & NA & NA & 165 \\
\hline \multirow[t]{4}{*}{2007} & B1 & 103 & 106 & 3 & 249 & 243 & 6 & 316 & 283 & 33 & 213 \\
\hline & B2 & 102 & 106 & 4 & 288 & 269 & 19 & 321 & 312 & 9 & 219 \\
\hline & A1 & 125 & 123 & 2 & 265 & 264 & 1 & 306 & 292 & 14 & 181 \\
\hline & $\mathrm{A} 2$ & 112 & NA & NA & 266 & NA & NA & 309 & NA & NA & 197 \\
\hline \multicolumn{12}{|l|}{ Hainich } \\
\hline \multirow[t]{3}{*}{2005} & B1 & 116 & 120 & 4 & 271 & 268 & 3 & 313 & 298 & 15 & 197 \\
\hline & A1 & 122 & 139 & 17 & 282 & 292 & 10 & 313 & 302 & 11 & 191 \\
\hline & $\mathrm{A} 2$ & 140 & NA & NA & 288 & NA & NA & 320 & NA & NA & 180 \\
\hline \multirow[t]{3}{*}{2006} & B1 & 117 & 120 & 3 & 295 & 283 & 12 & 320 & 309 & 11 & 203 \\
\hline & A1 & 119 & 129 & 10 & 294 & 295 & 1 & 325 & NA & NA & 206 \\
\hline & $\mathrm{A} 2$ & 126 & NA & NA & 274 & NA & NA & 325 & NA & NA & 199 \\
\hline \multirow[t]{3}{*}{2007} & B1 & NA & NA & NA & 277 & 267 & 10 & 304 & 299 & 5 & NA \\
\hline & A1 & NA & NA & NA & 277 & 281 & 4 & 307 & 301 & 6 & NA \\
\hline & A2 & NA & NA & NA & 277 & NA & NA & 306 & NA & NA & NA \\
\hline
\end{tabular}


varied (see Fig. 4). Regarding ash trees, observers agreed less about SOS dates but proposed very similar dates for SEN and EOS (data not shown).

At both sites, the observers suggested later SOS dates for beech trees than those derived from GF values (Table 1). At the Lägeren site, observers suggested earlier SOS dates for ash trees but for the Hainich site the opposite was true. The mean difference between observer- and GF-based SOS dates was $3 \mathrm{~d}$ at the Lägeren site and $8.5 \mathrm{~d}$ at the Hainich site. Higher discrepancies were found for SEN (8 d at Lägeren and $7 \mathrm{~d}$ at Hainich) and EOS dates (14 d at Lägeren and $10 \mathrm{~d}$ at Hainich). Generally, discrepancies were smaller for the ROIs mainly covered by ash trees than for those covered by beech trees at the Lägeren site; at the Hainich site, differences were independent of species.

\subsubsection{Phenology}

Phenological dates derived from digital camera images revealed similarities between the Hainich and Lägeren sites. The 2 forests are located in the midlatitudes and are influenced by the west wind drift; therefore, temperature and precipitation regimes are similar. In 2006, high mean daily air temperatures in the second half of June and in July, and increased autumn temperatures, compared to 2005 and 2007, were measured (Figs. 2 \& 3). Accordingly, a delayed leaf fall in
2006 (Piao et al. 2008) was observed at both sites. Our dates also showed an earlier spring green-up in 2007, compared to 2005 and 2006 (Luterbacher et al. 2007).

Observer- and GF-based dates showed tree-specific variability in phenology. This was mainly true for beech senescence at the Lägeren site (Fig. 4, Table 1). Notably, both observers and GF showed earlier SEN and EOS dates for the free-standing tall beech tree covered by the Beech 1 ROI, compared with the low standing beech trunks covered by the Beech 2 ROI. The GF-based SEN and EOS dates of ROIs covering ash trees at the Lägeren site showed less tree-specific variability (mean value of $6 \mathrm{~d}$ ). At the Hainich site, mean interannual variation observed for the 2 ROIs covering ash trees was higher in spring (SOS: $12 \mathrm{~d}$ ) than in autumn (SEN: 8.6 d, EOS: $2.6 \mathrm{~d}$ ).

Differences between beech and ash trees were detected in both observer- and GF-based results. ROIs covering ash trees showed a 1 to 3 wk delayed SOS date compared to beech green-up (Table 1). At the Lägeren site, differences between SEN and EOS dates of ash and beech trees extended to $38 \mathrm{~d}$ in 2006. Differences were related to tree-specific variability. GFbased leaf foliage durations (EOS - SOS) implied longer foliage duration periods for beech (191 to $219 \mathrm{~d}$ ) than for ash trees (165 to 197 d). At the Hainich site, fewer differences between SOS, SEN and EOS dates of ash and beech trees were determined. This was mainly true for 2007 and for the EOS dates.
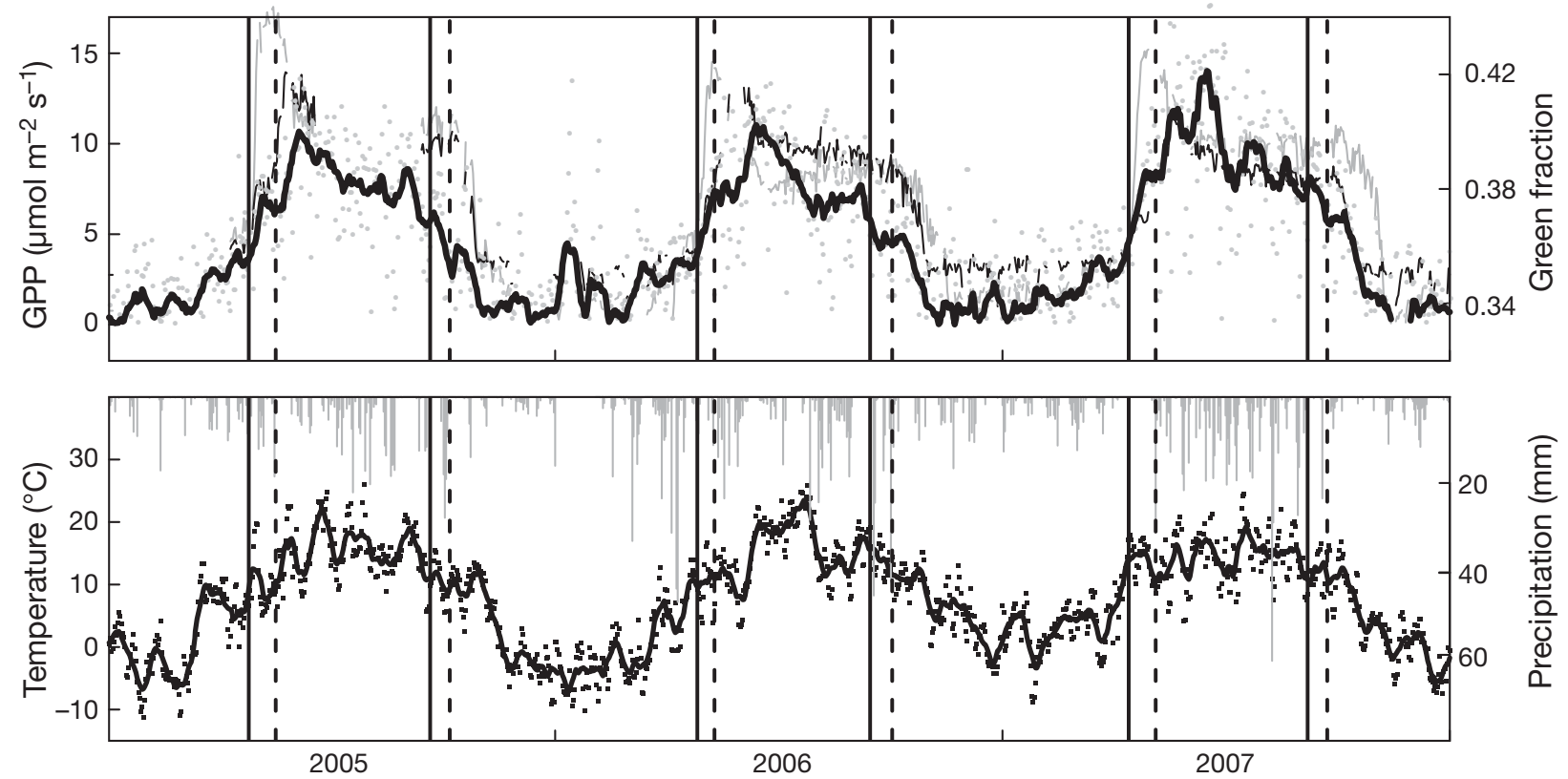

Fig. 2. Lägeren site. Upper panel: Gross primary productivity (GPP; black line: smoothed 10-window boxcar filter values, gray dots: mean daily raw values) and green fraction values of the Beech 1 (thin gray line) and Ash 1 regions of interest (thin black line) from 2005 to 2007. Lower panel: Daily precipitation sums (light gray bars), smoothed (10-window boxcar filter) mean daily temperature (black line) and mean daily temperature (black dots). Vertical lines indicate green-up and senescence dates of beech (solid lines) and ash trees (dashed lines) 

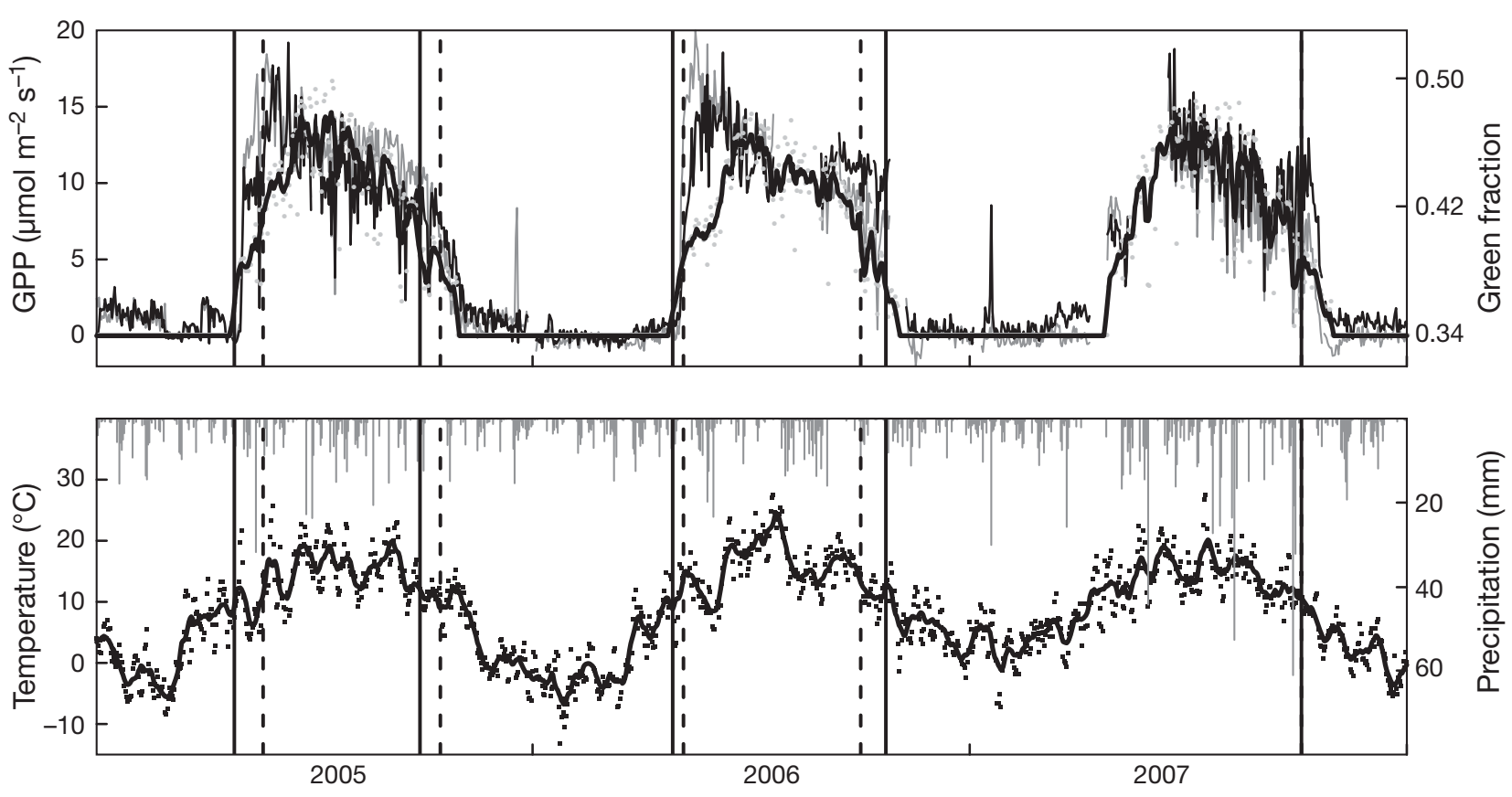

Fig. 3. As Fig. 2 but for the Hainich study site

Throughout the observation period, beech green-up (SOS) started $1 \mathrm{~d}$ later and senescence (SEN) about 1 to 2 wk later at the Hainich forest. In case of beech trees, the variation in tree-specific EOS dates (foliage loss) was higher than the variation between sites. The EOS date of ash trees was similar in 2005 and 2007, but earlier at the Lägeren site in 2006.

\subsection{Comparison to $\mathrm{CO}_{2}$ flux data}

\subsubsection{Green fraction and gross primary production}

The GF and GPP curves followed the same seasonal course (Figs. 2 \& 3) with an increase during spring, peak values in early summer with a subsequent slight decline, followed by a strong decline in autumn. A pronounced time lag between GPP and GF was found in early summer: GF reached maximum values earlier than GPP (Table 2). The time-lagged cross-correlation analyses for the Lägeren and Hainich sites (Table 3) gave further evidence of the significant high correlation between GF and GPP. Maximum correlation coefficients were as high as 0.86 at the Lägeren site and 0.93 at the Hainich site. Time lags ranged from 0 to 28 d (Lägeren) and 0 to $36 \mathrm{~d}$ (Hainich), depending on season and species. The highest correlation between GPP and GF was found in spring 2006 at the Lägeren site (DOY 95 to 135), and in autumn 2005 (DOY 240 to 330) at the Hainich site with a maximum time lag of $4 \mathrm{~d}$. Overall, lagged correlation was lowest in early summer (DOY 120 to 200 ) with positive time lags (0 to $36 \mathrm{~d}$ ) that reflect the time delay between peak values as described above. Overall, the correlation was higher for datasets from the Hainich site.

\subsubsection{Leaf emergence dates and spring gross primary} production

A linear regression model fit of GF (Beech 1 ROI) and mean daily GPP values indicated a strong linear relationship during the time period of beech green-up (Fig. 5). Regression coefficients ranged from 0.48 to 0.83 at the Lägeren site and from 0.54 to 0.92 at the Hainich site.

To identify possible $\mathrm{CO}_{2}$ gas exchange responses to leaf emergence of dominant tree species, mean daily GPP was smoothed by use of a 15-window boxcar filter for the Lägeren site and a 5-window boxcar filter for the Hainich site. At both sites, smoothed GPP sharply increased simultaneously with the leaf-out of beech trees (Figs. 6 \& 7). A consecutive increase in GPP was contemporaneous with ash green-up in 2005 and 2007, but showed a delay of several days in 2006. Generally, the stepwise increase in GPP was less pronounced at the Hainich site.

However, changes in GPP were also correlated with mean daily air temperature (smoothed by use of a 10window boxcar filter) and precipitation events during green-up especially at the Hainich site. At both sites, the phase of stagnating increase in GPP in 2006 (located around DOY 135 to 145) coincided with low temperatures and high amounts of precipitation. In 2007, GPP varied simultaneously with mean air temperatures. 

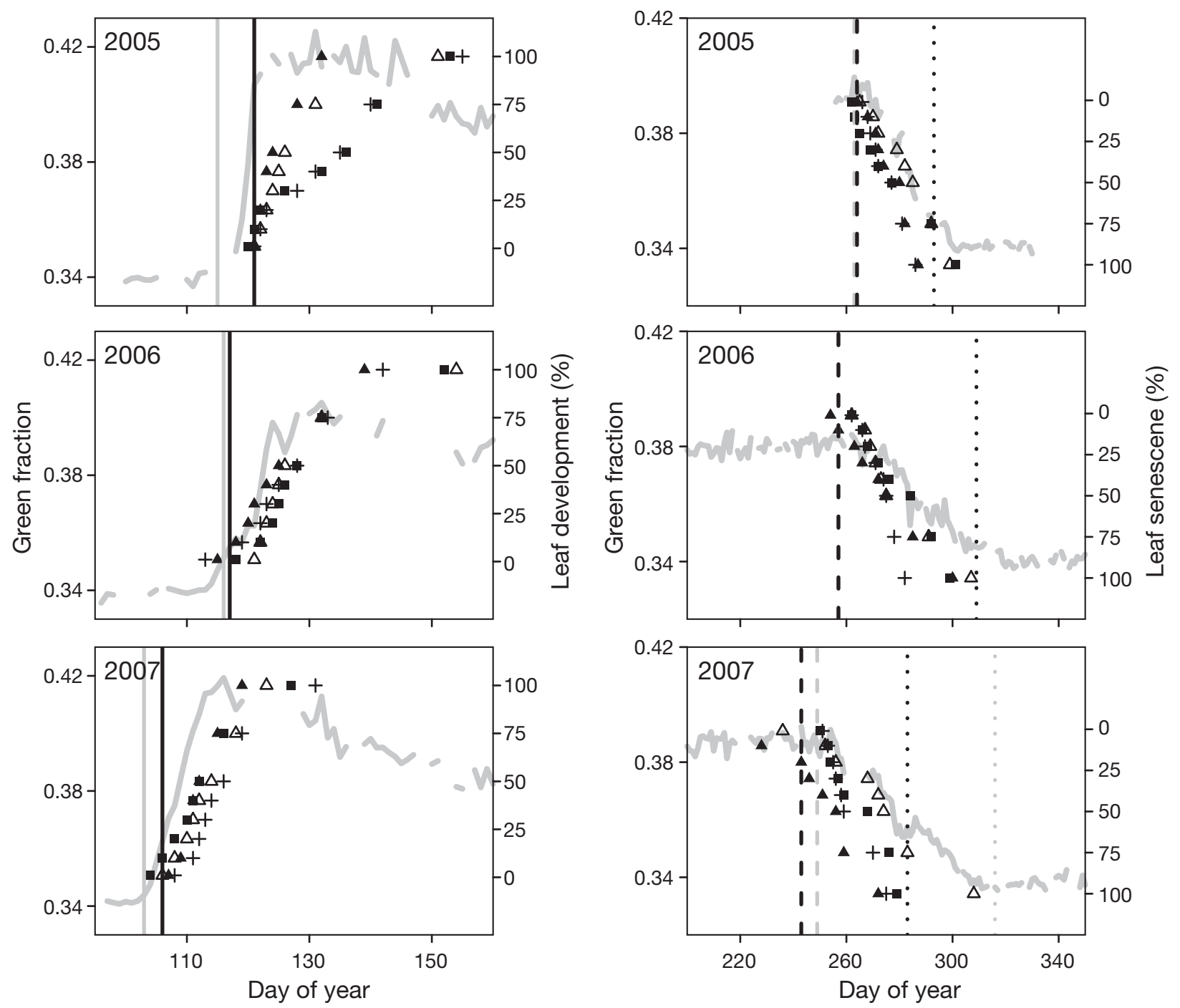

Fig. 4. Green fraction values for the Beech 1 region of interest (solid gray line) at the Lägeren forest and phenological observations made by visual image analysis (black symbols). The different symbols represent the 4 different observers. Vertical lines indicate the start of growing season (solid), start of leaf senescence (dashed) and end of growing season (dotted) dates estimated by automated (black) and visual image analyses (gray, mean observation dates)

\section{DISCUSSION}

\subsection{Phenology estimates by use of camera images}

The present study showed encouraging results about the use of digital camera images for automated observation of seasonal changes in the canopy development. Continuous time series of changing color values provide reliable information on the vegetation state at a high spatial and temporal resolution. However, the algorithm proposed here was only tested for 2 forests under the specific climatic and ecological conditions found. Its applicability in other ecosystems, such as arctic grasslands or tropical evergreen broadleaf forests, needs to be evaluated.
Differences between observer- and GF-based data can be explained when detailed knowledge on species included in the ROI, their phenological characteristics and meteorological conditions are taken into account. The discrepancies between SOS dates of beech trees are probably a relict of smoothing procedures during the first- and second-derivative analyses procedure performed to derive phenological dates (cf. Section 2.4). We further assume that a high sensitivity of the cameras' color sensor to the appearance of the first green leaf tips after bud break results in earlier GF-based leaf-out dates than those suggested by the observers. SOS dates of ash trees are affected by other species growing in the same ROI, if other species green-up earlier (e.g. beech saplings, understory vegetation). GF 
Table 2. Important ecological and meteorological parameters at the Lägeren and Hainich sites from 2005 to 2007 . GPP max $_{\text {: day of }}$ year (DOY) with maximum gross primary productivity value; $\mathrm{GF}_{\operatorname{maxB}}$, $\mathrm{GF}_{\operatorname{maxA}}$ : DOY with the maximum green fraction value of beech and ash, respectively; $\mathrm{GPP}_{\text {sum }}$ : annual sum of GPP

\begin{tabular}{|c|c|c|c|c|c|c|c|}
\hline & & $\begin{array}{l}\text { Precipitation } \\
\text { sum (mm) }\end{array}$ & $\begin{array}{c}\text { Mean temp. } \\
\left({ }^{\circ} \mathrm{C}\right)\end{array}$ & $\begin{array}{l}\mathrm{GPP}_{\max } \\
(\mathrm{DOY})\end{array}$ & $\begin{array}{l}\mathrm{GF}_{\operatorname{maxB}} \\
(\mathrm{DOY})\end{array}$ & $\begin{array}{l}\mathrm{GF}_{\operatorname{maxA}} \\
\text { (DOY) }\end{array}$ & $\begin{array}{c}\mathrm{GPP}_{\text {sum }} \\
\left(\mathrm{gC} \mathrm{m}^{-2} \mathrm{yr}^{-1}\right)\end{array}$ \\
\hline Lägeren & $\begin{array}{l}2005 \\
2006 \\
2007\end{array}$ & $\begin{array}{l}708 \\
914 \\
913\end{array}$ & $\begin{array}{l}7.43 \\
7.96 \\
8.10\end{array}$ & $\begin{array}{l}158 \\
171 \\
167\end{array}$ & $\begin{array}{l}135 \\
131 \\
118\end{array}$ & $\begin{array}{l}158 \\
153 \\
139\end{array}$ & $\begin{array}{l}1944 \\
2045 \\
2325\end{array}$ \\
\hline Hainich & $\begin{array}{l}2005 \\
2006 \\
2007\end{array}$ & $\begin{array}{r}736 \\
660 \\
1047\end{array}$ & $\begin{array}{l}8.12 \\
8.66 \\
8.82\end{array}$ & $\begin{array}{l}197 \\
182 \\
188\end{array}$ & $\begin{array}{l}143 \\
136 \\
\text { NA }\end{array}$ & $\begin{array}{l}161 \\
159 \\
\text { NA }\end{array}$ & $\begin{array}{l}1751 \\
1652 \\
1666\end{array}$ \\
\hline
\end{tabular}

values at the Lägeren site thus only increased when ash leaves started covering branches, stems and other previously non-green tree parts in the ROI (Ahrends et al. 2008). In contrast, observer-based SOS dates of Ash 1 ROI at the Hainich site were several days later com-

Table 3. Time lag (d) between phenological green fraction (GF) values and gross primary productivity (GPP) determined for selected time windows as specified by day of year (DOY). Time lags were determined via cross correlation assuming that GF leads GPP. ROI: region of interest; CCF: cross-correlation function; ns: not significant $(p>0.05)$

\begin{tabular}{|c|c|c|c|c|c|c|}
\hline \multirow{2}{*}{ Year } & \multicolumn{3}{|c|}{ Beech (Beech 1 ROI) } & \multicolumn{3}{|c|}{ Ash (Ash 1 ROI) } \\
\hline & DOY & Lag & CCF & DOY & Lag & $\mathrm{CCF}$ \\
\hline \multicolumn{7}{|l|}{ Lägeren } \\
\hline 2005 & $95-130$ & 0 & 0.74 & $115-145$ & 0 & ns \\
\hline 2006 & & 0 & 0.83 & & -2 & 0.81 \\
\hline 2007 & & 0 & 0.81 & & -1 & 0.57 \\
\hline 2005 & $120-200$ & 24 & 0.37 & $120-200$ & 5 & 0.63 \\
\hline 2006 & & 18 & 0.46 & & 8 & 0.39 \\
\hline 2007 & & 28 & 0.40 & & 4 & 0.31 \\
\hline 2005 & $200-300$ & 0 & 0.45 & $200-300$ & -8 & 0.45 \\
\hline 2006 & & 0 & 0.49 & & 1 & 0.54 \\
\hline 2007 & & 0 & 0.74 & & 0 & 0.73 \\
\hline 2005 & $240-330$ & 6 & 0.61 & $240-330$ & 0 & 0.57 \\
\hline 2006 & & 0 & 0.60 & & -4 & 0.58 \\
\hline 2007 & & 0 & 0.75 & & 2 & 0.74 \\
\hline 2005 & $1-365$ & 0 & 0.62 & $1-365$ & 0 & 0.71 \\
\hline 2006 & & 1 & 0.75 & & -3 & 0.77 \\
\hline 2007 & & 2 & 0.79 & & -1 & 0.86 \\
\hline \multicolumn{7}{|l|}{ Hainich } \\
\hline 2005 & $95-130$ & -4 & 0.76 & $115-145$ & 0 & 0.73 \\
\hline 2006 & & 0 & 0.86 & & -1 & 0.90 \\
\hline 2007 & & 0 & 0.84 & & $\mathrm{~ns}$ & ns \\
\hline 2005 & $120-200$ & 36 & 0.27 & $120-200$ & 6 & 0.41 \\
\hline 2006 & & 31 & 0.34 & & 25 & 0.49 \\
\hline 2007 & & 0 & 0.73 & & 0 & 0.80 \\
\hline 2005 & $200-300$ & 0 & 0.69 & $200-300$ & 0 & 0.65 \\
\hline 2006 & & -1 & 0.62 & & -1 & 0.41 \\
\hline 2007 & & 0 & 0.77 & & 0 & 0.66 \\
\hline 2005 & $240-330$ & 0 & 0.93 & $240-330$ & 0 & 0.93 \\
\hline 2006 & & -1 & 0.89 & & -1 & 0.89 \\
\hline 2007 & & 0 & 0.90 & & 0 & 0.90 \\
\hline 2005 & $1-365$ & 0 & 0.88 & $1-365$ & 0 & 0.88 \\
\hline 2006 & & 0 & 0.88 & & 0 & 0.89 \\
\hline 2007 & & 0 & 0.93 & & 0 & 0.92 \\
\hline
\end{tabular}

pared to GF-based SOS. The reason for this is related to the fact that it is not possible to distinguish firmly between ash and beech trees using the curvature shape of GF for the Ash 1 ROI at the Hainich site. Changing camera positions and a short distance to the observed trees resulted in a strong influence of the background vegetation on estimated SOS dates in this case. Differences between $\mathrm{GF}_{\text {max }}$ dates for ROIs covering beech trees are assumed to be caused by additional influences of changing color saturation of the leaves due to chlorophyll accumulation and changing leaf inclination angles that might affect the observers' impression of percent leaf cover. Differences between GF- and observer-based SEN dates were probably caused by difficulties of the observers in specifying SEN dates for beech trees due to slow leaf coloring processes (Delpierre et al. 2009a). Ash trees shed their leaves green and are completely leafless when dormancy starts. Observers thus can more easily determine SEN and EOS dates. In contrast, brown leaves often remain on beech trees during winter, thereby causing systematic differences between observer- and GF-based EOS dates.

Field observations of tree phenology traditionally refer to specific stages of plant development, such as bud break, percent leaf emergence, flowering, fruiting, percent leaf coloring and percent leaf fall. These observations are accurate, but are often only valid for one specific, often free-standing, tree. Additionally, observation rules are often not comparable, and observers, the date of observation and trees observed can change from year to year. Using an approach based on visual image interpretation allows the observation of individual trees and, based on the experience of the observer, separation of the target tree from background objects, such as trees located behind the target tree, understory vegetation, buildings or sky. However, the accuracy of this validation approach is based on the observer's experience (Sparks et al. 2006), image resolution and meteorological disturbance. Percent development or senescence can only be approximated by visual image interpretation due to 

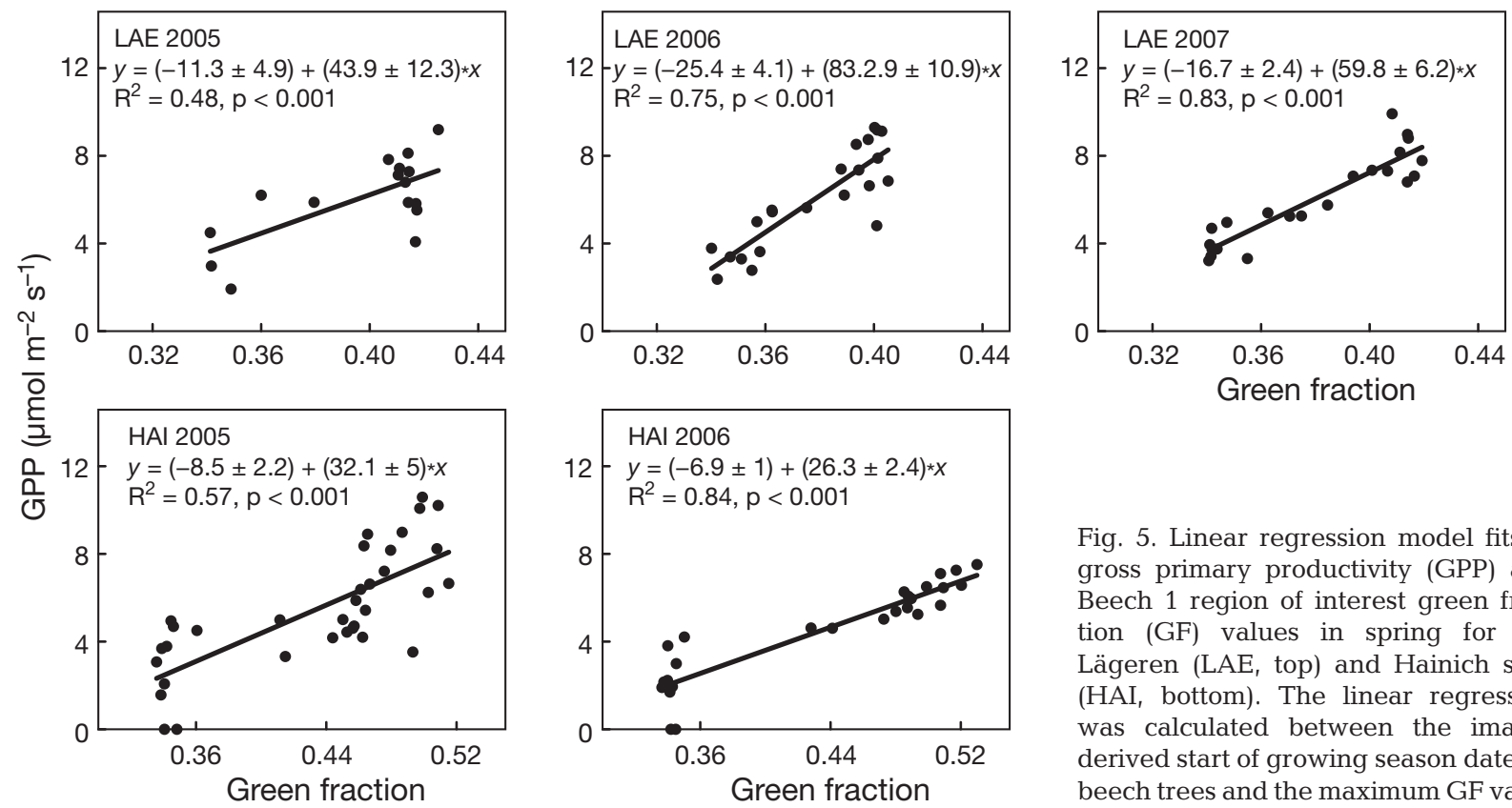

Fig. 5. Linear regression model fits of
gross primary productivity (GPP) and
Beech 1 region of interest green frac-
tion (GF) values in spring for the
Lägeren (LAE, top) and Hainich sites
(HAI, bottom). The linear regression
was calculated between the image-
derived start of growing season date for
beech trees and the maximum GF value

the low dimensionality of the images. An automated image analysis, as presented here, is very objective with respect to the methodological and site-specific stability. We assume that the automated analysis of digital image data is more accurate in terms of rates and relative changes in the vegetation compared to field observations or visual image analysis. It allows for accurate interannual comparison, although valid for the canopy rather than for single trees. However, field studies and, to a lesser degree, visual image analyses are more accurate and far less prone to errors with respect to the detection of specific phenological phases such as flowering, fruiting or bud breaking.
Uncertainties in automated detection of phenological dates are, for example, caused by changing illumination conditions, background effects due to multiple trees and/or other objects covered by the analyzed ROIs, limited image resolution, changes in observation geometry and meteorological disturbance (Ahrends et al. 2008). The observation of multiple species with cameras depends on expert knowledge and thus remains a challenge, especially if different species are greening-up simultaneously. In the present study, such uncertainties influenced the determination of SOS dates for the different ash trees. GF-based dates were strongly affected by species that green-up earlier and
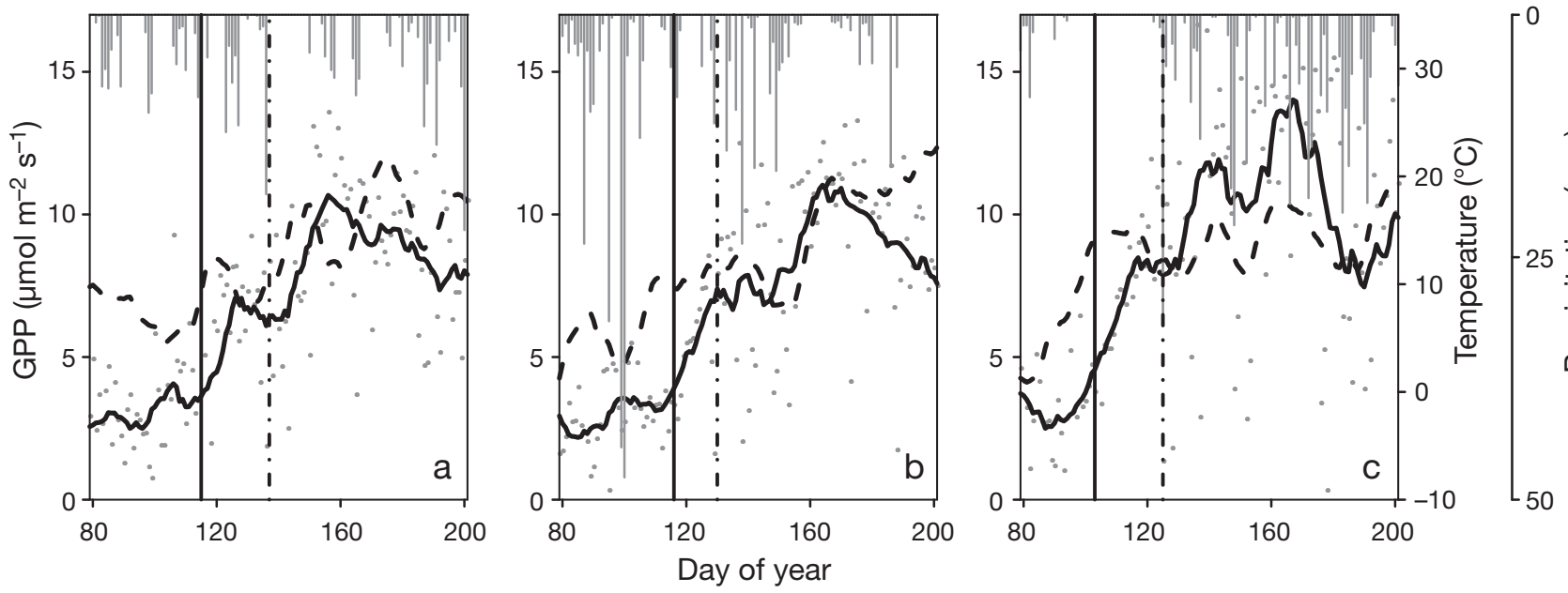

Fig. 6. Raw (gray dots) and smoothed (solid black line) gross primary productivity (GPP), smoothed mean daily air temperature (dashed black line) and daily precipitation sums (gray bars) at the Lägeren site in (a) 2005, (b) 2006 and (c) 2007. Vertical lines indicate start of growing season dates of beech trees (solid line) and latest green-up of ash trees (dot-dash line) 

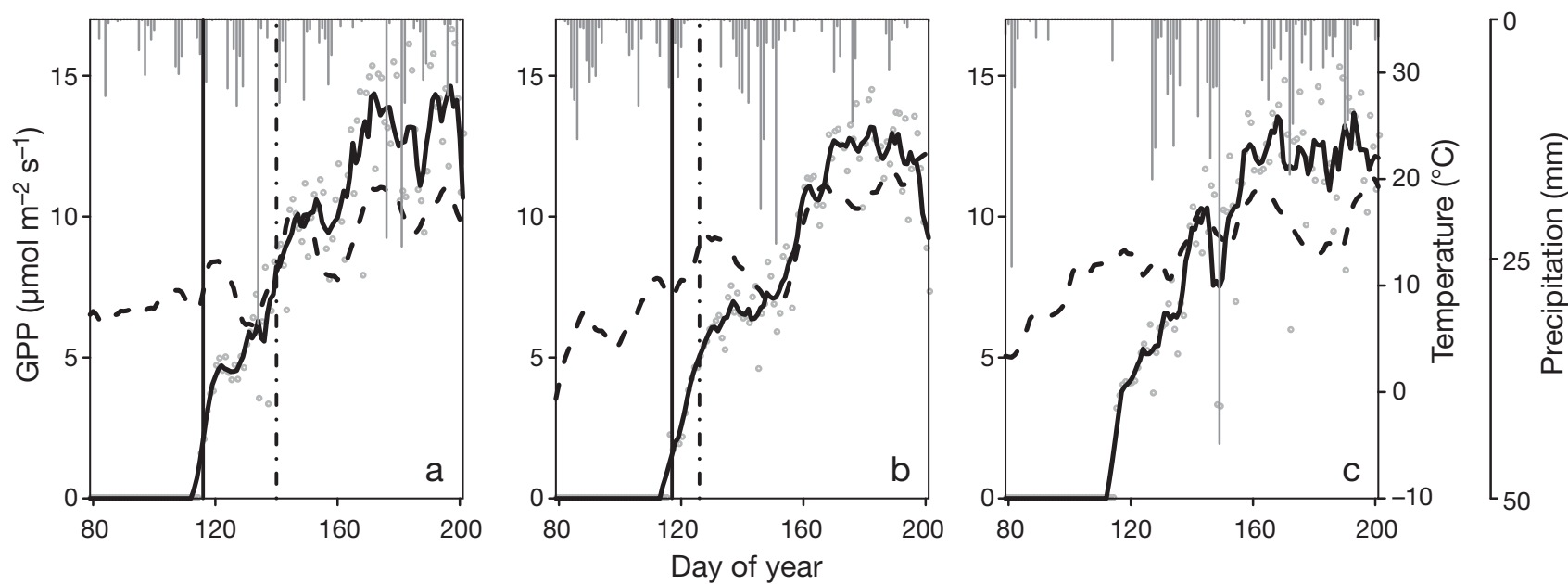

Fig. 7. As Fig. 6 but for the Hainich study site

were additionally influenced by precipitation events. At the Hainich site, images were not regularly taken at the same hour of the day. Ahrends et al. (2008) showed that this leads to moderate uncertainties in GF values due to differences in the sun angle. In addition, several changes in the camera's position resulted in changes in the vegetation fraction covered by the ROIs. The distance between the camera and the trees is short. Therefore, single leaves, especially ash leaves with their bright backsides, lead to changes in the GF when their position changes due to wind. As a consequence, GF-based data at the Hainich site scatter strongly compared to the Lägeren data. We conclude that camera installations with a view to observing phenology need to consider stability of the camera's FOV and tree species covered by the images. Additionally, visual and knowledge-based control and the integration of detailed field data in the interpretation of the results are advisable. A combination of field data and image data could complement phenological observation of different trees and different species at the ecosystem level.

\subsection{Comparisons to $\mathrm{CO}_{2}$ data}

In general, GPP and GF showed the same temporal patterns during the observation period. The significant increase in spring and decrease in autumn was concurrently observed in both variables and is caused by their interaction and the strong dependence of both plant phenology and physiology on meteorological conditions in forest ecosystems (Körner 2006, Cleland et al. 2007).

During the 3 yr of observation, we found that the managed Lägeren forest had higher annual GPP sums compared to the Hainich forest. Differences in local meteorological conditions and soil nutrient availability and management might be the major explanatory factors. Additionally, at the Lägeren site coniferous trees form a major part of the canopy and thus contribute to GPP during winter. It is extremely unlikely that the differences are caused by the different approaches to estimate carbon fluxes from NEE measurements and from bottom-up modelling, because the eddy covariance approach at Hainich was biased by advection during the nighttime and consequently resulted in a lower GPP than the chamber-derived bottom-up model (Kutsch et al. 2008). At the Lägeren site, the highest GPP levels were recorded in 2007, when bud break was about 10 d earlier than in 2005 and 2006 (Table 3). This agrees with studies that showed increased carbon gains due to early leaf development (e.g. Morecroft et al. 2003, Niemand et al. 2005). However, at the Hainich site GPP production was highest in 2005, possibly due to higher photosynthetic photon flux density in summer and autumn compared with 2007 (data not shown). This shows that the influence of phenological dates on annual GPP can be overruled by the actual meteorological conditions. Thus, phenology, as it is describing the actual state of the vegetation, probably shows stronger relations with the maximum photosynthetic capacity of the leaves than with actual GPP. Perfect correlations to actual GPP values cannot be expected and maximum GPP may better correlate to $\mathrm{GF}$, as it does to the fraction of photosynthetically active radiation (Running et al. 2004). Limiting conditions due to variation in environmental parameters, such as temperature, incoming radiation and soil moisture, reduce actual GPP. We did not derive the maximum GPP because the GPP measured by eddy covariance is a mixed signal over all species. Detailed information on species contribution to total GPP could be obtained by a combined approach of digital images, 
eddy covariance, chamber measurements and modelling.

The Lägeren forest has a lower tree density, compared with the Hainich site, due to forest management and the presence of minor deforested areas (e.g. meadow areas, deforested by the 1999 storm Lothar), but individual trees are taller (up to $43 \mathrm{~m}$ at Lägeren vs. $37 \mathrm{~m}$ at Hainich). Higher percentages of deforested areas and early greening meadow vegetation may explain the higher GPP amounts calculated for the Lägeren site before beech green-up. Beech is the dominant tree species in both forests (Eugster et al. 2007, Kutsch et al. 2008). This is shown in the pronounced increase of GPP at both sites after beech green-up. The time lag between maximum GPP and the timing of maximum GF values may be explained by the time lag between complete leaf expansion and the development of full photosynthetic capacity in beech trees (Schulze 1970, Morecroft et al. 2003). After complete expansion, the young, transparent, light green beech leaves showed high GF values. Within a few weeks, chlorophyll was accumulated, the leaves became darker and thicker and GF values decreased while photosynthetic activity increased. In addition, the time lag is assumed to be related to species that leaf-out later but have a significant contribution to GPP.

Generally, maximum GPP at the Hainich site was achieved several days later compared to the Lägeren site ( $41 \mathrm{~d}$ in 2005, $18 \mathrm{~d}$ in 2006 and $30 \mathrm{~d}$ in 2007). These differences are likely caused by the local meteorology and the site-specific differences in species composition. Shorter time lags in 2006 might be caused by the superior influence on GPP of extremely high temperatures and lack of precipitation in late June and July at both sites.

In agreement with GF-based phenology, crosscorrelation analyses for early summer showed that time lags differed for ash and beech trees. Contrary to this, cross-correlation analyses on an annual time scale showed that time series of GPP and GF were significantly correlated with a time lag around $0 \mathrm{~d}$ for both species. GF and GPP data were both affected by daily local weather conditions such as air temperature and incoming radiation (Chapin et al. 2002, Ahrends et al. 2008). As a consequence, time series also were correlated during summer and dormancy. The high correlation during spring was possibly enhanced by the light and temperature dependency of both GPP increase (e.g. Welp et al. 2007) and rate of leaf expansion (Rawson \& Hindmarsh 1982, Tamaki et al. 2002).

In spring, large variation in temperature and possibly radiation result in large fluctuations in photosynthesis (Chapin et al. 2002). These high frequency GPP fluctuations driven by meteorology masked influences of tree phenology on the temporal variability of GPP. A dominant influence of phenology on GPP is very likely for beech trees but remains unclear for ash trees and other subdominant species.

At the Lägeren site, additional influences of coniferous trees on GPP have to be considered. Longer time series are needed to study the complex interactions between gas exchange, meteorology and the phenology of each species and each individual tree (Schulze 1970, Körner 2006). Extended analyses of GF values based on longer time series jointly with GPP derived from harmonized approaches at both sites and additional meteorological data, such as radiation and vapour pressure deficit, are needed to increase certainty about possible superior influences of phenology on GPP.

Terrestrial carbon cycle research benefits from valuable ecological information contained in camera-based phenology since the images offer extended analysis possibilities, especially with respect to species-level variability at flux tower sites. Quantitative information on changing color values at high temporal and spatial resolution might be a key component for processbased ecosystem studies. Digital cameras have the potential to observe phenological responses to specific meteorological conditions such as drought periods resulting in earlier leaf senescence, particularly for beech trees (Kutsch et al. 2009). Further studies could analyze the possibilities and limitations of using camera images to detect plant water stress which may be related to $\mathrm{CO}_{2}$ assimilation characteristics. Objective information on interannual variation in phenological dates can improve the confidence of phenology included in carbon flux modelling approaches. Additionally, images provide validation data for remote sensing studies; therefore, the accuracy of satellite data which are needed for spatial up-scaling of the $\mathrm{CO}_{2}$ fluxes (Running et al. 1999, Xiao et al. 2004, Gilmanov et al. 2005) can be improved. Thus, camera images might be useful for bridging the gap between qualitative differences and spatial resolution differences of flux measurements between the plot and regional scales (Badeck et al. 2004).

\section{CONCLUSIONS}

High-resolution RGB digital camera images of forest canopies provide reliable information on leaf emergence dates, start of senescence and start of dormancy of dominant tree species. An automated analysis of vegetation developmental stages is possible based on the curvature shape of the GF. The use of a fixed FOV in combination with a fixed hour of day for image capture and an appropriate distance between camera and target is crucial for automated phenological analyses. RGB cameras expand the pool of possible phenological 
observation methods, but image interpretation relies on expert knowledge and images cannot completely replace field observations of different tree species.

At the Hainich and Lägeren sites, GPP varied simultaneously with GF values derived from image regions that mainly covered beech trees as the dominant tree species. A major influence of the phenology of subdominant tree species could not be confirmed, due to masking weather influences. However, the high correlation between camera-based phenology and GPP showed significant dependencies of $\mathrm{CO}_{2}$ exchange processes on the developmental stage of the dominant tree species, mainly during spring green-up.

Therefore, the use of digital images in objective and continuous phenological monitoring could help to improve our present scientific understanding of ecophysiological processes in trees and forest canopies. Furthermore, the inclusion of image-based, objective phenological data into ecological modelling approaches offers the great opportunity to advance model accuracy and reliability.

Acknowledgements. This project is funded by the Swiss Federal Department of Home Affairs FDHA: State 414 Secretariat for Education and Research SER, SBF No. CO5.0032. We thank C. Hueglin (EMPA) who provided NABEL precipitation data (BAFU).

\section{LITERATURE CITED}

Ahl DE, Gower ST, Burrows SN, Shabanov NV, Myneni RB, Knyazikhin Y (2006) Monitoring spring canopy phenology of a deciduous broadleaf forest using MODIS. Remote Sens Environ 104:88-95

Ahrends HE, Brügger R, Stöckli R, Schenk J and others (2008) Quantitative phenological observations of a mixed beech forest in northern Switzerland with digital photography. J Geophys Res 113:G04004, doi:10.1029/2007JG000650

- Arora VK, Boer GJ (2005) A parameterization of leaf phenology or the terrestrial ecosystem component of climate models. Glob Change Biol 11:39-59

Badeck FW, Bondeau A, Böttcher K, Doktor D, Lucht W, Schaber J, Sitch S (2004) Responses of spring phenology to climate change. New Phytol 162:295-309

Baldocchi DD (2003) Assessing the eddy covariance technique for evaluating carbon dioxide exchange rates of ecosystems: past, present and future. Glob Change Biol 9:479-492

Baldocchi DD, Black TA, Curtis PS, Falge E and others (2005) Predicting the onset of net carbon uptake by deciduous forests with soil temperature and climate data: a synthesis of FLUXNET data. Int J Biometeorol 49:377-387

Barr AG, Black TA, Hogg EH, Griffis TJ and others (2007) Climatic controls on the carbon and water balances of a boreal aspen forest, 1994-2003. Glob Change Biol 13: 561-576

Berninger F (1997) Effects of drought and phenology on GPP in Pinus sylvestris: a simulation study along a geographical gradient. Funct Ecol 11:33-43

Betancourt JL, Schwartz MD, Breshears DD, Cayan DR and others (2005) Implementing a U.S. National Phenology
Network. EOS Trans Am Geophys Union 86 doi:10.1029/ 2005EO510005

Black TA, Chen WJ, Barr AG, Arain MA and others (2000) Increased carbon sequestration by a boreal deciduous forest in years with a warm spring. Geophys Res Lett 27: 1271-1274

Chapin FS III, Matson PA, Mooney HA (2002) Principles of terrestrial ecosystem ecology. Springer-Verlag, New York

Chiang JM, Brown KJ (2007) Improving the budburst phenology subroutine in the forest carbon model PnET. Ecol Model 205:515-526

Cleland EE, Chuine I, Menzel A, Mooney HA, Mark D (2007) Shifting plant phenology in response to global change. Trends Ecol Evol 22:357-365

Delpierre N, Dufrêne E, Soudani K, Ulrich E, Cecchini S, Boé J, Frabcois C (2009a) Modelling interannual and spatial variability of leaf senescence for three deciduous tree species in France. Agric For Meteorol 139:938-948

Delpierre N, Soudani K, François C, Köstner B and others (2009b) Exceptional carbon uptake in European forests during the warm spring of 2007: a data-model analysis. Glob Change Biol 15:1455-1474

Dunn AL, Barford CC, Wofsy SC, Goulden ML, Daube BC (2007) A long-term record of carbon exchange in a boreal black spruce forest: means, responses to interannual variability, and decadal trends. Glob Change Biol 13:577-590

Eugster W, Kling G, Jonas T, McFadden JP, Wuest A, MacIntyre $\mathrm{S}$, Chapin FS (2003) $\mathrm{CO}_{2}$ exchange between air and water in an Arctic Alaskan and midlatitude Swiss lake: importance of convective mixing. J Geophys Res 108:4362, doi:10.1029/2002JD002653

Eugster W, Zeyer K, Zeeman M, Michna P, Zingg A, Buchmann N, Emmenegger L (2007) Methodical study of nitrous oxide eddy covariance measurements using quantum cascade laser spectrometery over a Swiss forest. Biogeosciences 4:927-939

> Fisher JI, Mustard JF, Vadeboncoeur MA (2006) Green leaf phenology at Landsat resolution: scaling from the field to the satellite. Remote Sens Environ 100:265-279

Fitzjarrald DR, Otávio DR, Acevedo C, Moore K (2001) Climatic consequences of leaf presence in the eastern United States. J Clim 14:598-614

Foken T, Wichura B (1996) Tools for quality assessment of surface-based flux measurements. Agric For Meteorol 78: 83-105

Gilmanov TG, Tieszen LL, Wylie BK, Flanagan LB and others (2005) Integration of $\mathrm{CO}_{2}$ flux and remotely sensed data for primary production and ecosystem respiration analyses in the Northern Great Plains: potential for quantitative spatial extrapolation. Glob Ecol Biogeogr 14:271-292

Göckede M, Foken T, Aubinet M, Aurela M and others (2008) Quality control of CarboEurope flux data - Part 1: coupling footprint analyses with flux data quality assessment to evaluate sites in forest ecosystems. Biogeosciences 5:433-450

Goulden ML, Munger JW, Fan SM, Daube BC, Wofsy SC (1996) Exchange of carbon dioxide by a deciduous forest: response to interannual climate variability. Science 271: $1576-1578$

Hiller R, Zeeman MJ, Eugster W (2008) Eddy-covariance flux measurements in the complex terrain of an Alpine valley in Switzerland. Boundary-Layer Meteorol 127:449-467

> Keeling CD, Chin JFS, Whorf TP (1996) Increased activity of northern vegetation inferred from atmospheric $\mathrm{CO}_{2}$ measurements. Nature 382:146-149

Knohl A, Baldocchi DD (2008) Effects of diffuse radiation on canopy gas exchange processes in a forest ecosystem. J Geophys Res 113:G02023, doi:10.1029/2007JG000663 
Knohl A, Schulze E, Kolle O, Buchmann N (2003) Large carbon uptake by an unmanaged 250-year-old deciduous forest in Central Germany. Agric For Meteorol 118:151-167

Körner C (2006) Plant $\mathrm{CO}_{2}$ responses: an issue of definition, time and resource supply. New Phytol 172:393-411

Kutsch WL, Kolle O, Rebmann C, Knohl A, Ziegler W, Schulze ED (2008) Advection and resulting $\mathrm{CO}_{2}$ exchange uncertainty in a tall forest in central Germany. Ecol Appl 18: 1391-1405

Kutsch WL, Wirth C, Kattge J, Nöllert S, Herbst M, Kappen L (2009) Ecophysiological characteristics of large, mature trees and their consequences for old-growth forest productivity. In: Wirth C (ed) Old-growth forests. Ecological Studies, Springer (in press)

Leinonen I, Kramer K (2002) Applications of phenological models to predict the future carbon sequestration potential of boreal forests. Clim Change 55:99-113

Linderholm HW (2006) Growing season changes in the last century. Agric For Meteorol 137:1-14

> Luterbacher J, Liniger MA, Menzel A, Estrella N and others (2007) The exceptional European warmth of autumn 2006 and winter 2007: historical context, the underlying dynamics, and its phenological impacts. Geophys Res Lett 34:L12704, doi:10.1029/2007GL029951

McMillen RT (1988) An eddy correlation technique with extended applicability to non-simple terrain. BoundaryLayer Meteorol 43:231-245

Menzel A (2002) Phenology: its importance to the global change community. Clim Change 54:379-385

Morecroft MD, Stokes VJ, Morison JIL (2003) Seasonal changes in the photosynthetic capacity of canopy oak (Quercus robur) leaves: the impact of slow development on annual carbon uptake. Int J Biometeorol 47:221-226

Nemani R, White M, Thornton P, Nishida K, Reddy S, Jenkins J, Running S (2002) Recent trends in hydrologic balance have enhanced the terrestrial carbon sink in the United States. Geophys Res Lett 29:1468, doi:10.1029/2002GL 014867

> Niemand C, Köstner B, Prasse H, Grünwald T, Bernhofer C (2005) Relating tree phenology with annual carbon fluxes at Tharandt forest. Meteorol Z 14:197-202

Obrist D, Verburg PSJ, Young MH, Coleman JS, Schorran DE, Arnone JA (2003) Quantifying the effects of phenology on ecosystem evapotranspiration in planted grassland mesocosmos using EcoCELL technology. Agric For Meteorol 118:173-183

Papale D, Reichstein M, Aubinet M, Canfora E and others (2006) Towards a standardized processing of net ecosystem exchange measured with eddy covariance technique: algorithms and uncertainty estimation. Biogeosciences 3: 571-583

Peñuelas J, Filella I (2001) Responses to a warming world. Science 294:793-794

Piao S, Friedlingstein P, Ciais P, Viovy N, Demarty J (2007) Growing season extension and its impact on terrestrial carbon cycle in the Northern Hemisphere over the past 2 decades. Global Biogeochem Cycles 21:GB3018, doi:10. 1029/2006GB002888

Piao S, Ciais P, Friedlingstein P, Peylin P and others (2008) Net carbon dioxide losses of northern ecosystems in response to autumn warming. Nature 451:49-52

Rawson HM, Hindmarsh JH (1982) Effects of temperature on leaf expansion in sunflower. Aust J Plant Physiol 9:209-219

Reichstein M, Falge E, Baldocchi DD, Papale D and others
(2005) On the separation of net ecosystem exchange into assimilation and ecosystem respiration: review and improved algorithm. Glob Change Biol 11:1424-1439

Richardson AD, Jenkins JP, Braswell BH, Hollinger DY, Ollinger SV, Smith M (2007) Use of digital webcam images to track spring green-up in a deciduous broadleaf forest. Oecologia 152:323-334

Richardson AD, Hollinger DY, Dail DB, Lee JT, Munger JW, O'Keefe J (2009a) Influence of spring phenology on seasonal and annual carbon balance in two contrasting New England forests. Tree Physiol 29:321-331

Richardson AD, Braswell BH, Hollinger DY, Jenksins JP, Ollinger SV (2009b) Near-surface remote sensing of spatial and temporal variation in canopy phenology. Ecol Appl 19:1417-1428

Running SW, Baldocchi DD, Turner D, Gower ST, Bakwin P, Hibbard K (1999) A global terrestrial monitoring network integrating tower fluxes, flask sampling, ecosystem modeling and EOS satellite data. Remote Sens Environ 70: 108-127

Running SW, Nemani RR, Heinsch FA, Zhao M, Reeves M, Hashimoto H (2004) A continuous satellite-derived measure of global terrestrial primary production. Bioscience 54:547-560

Schulze ED (1970) Der $\mathrm{CO}_{2}$-Gaswechsel der Buche. Flora 159: $177-232$

Schwartz MD, Reed BC (1999) Surface phenology and satellite sensor-derived onset of greenness: an initial comparison. Int J Remote Sens 20:3451-3457

Schwartz MD, Ahas R, Aasa A (2006) Onset of spring starting earlier across the Northern Hemisphere. Glob Change Biol 12:343-351

Sparks TH, Huber K, Croxton PJ (2006) Plant development scores from fixed-date photographs: the influence of weather variables and recorder experience. Int $\mathrm{J}$ Biometeorol 50:275-279

> Studer S, Stöckli R, Appenzeller C, Vidale PL (2007) A comparative study of satellite and ground-based phenology. Int J Biometeorol 51:405-414

Tamaki M, Kondo T, Itani T, Goto Y (2002) Temperature responses of leaf emergence and leaf growth in barley. J Agric Sci 138:17-20

van Vliet AJH, de Groot R, Bellens Y, Braun P and others (2003) The European Phenology Network. Int J Biometeorol 47:202-212

Welp LR, Randerson JT, Liu HP (2007) The sensitivity of carbon fluxes to spring warming and summer drought depends on plant functional type in boreal forest ecosystems. Agric For Meteorol 147:172-185

- White MA, Nemani RR (2003) Canopy duration has little influence on annual carbon storage in the deciduous broadleaf forest. Glob Change Biol 9:967-972

Xiao X, Zhang Q, Braswell B, Urbanski S and others (2004) Modeling gross primary production of a deciduous broadleaf forest using satellite images and climate data. Remote Sens Environ 91:256-270

Zhang X, Friedl MA, Schaaf CB, Strahler AH and others (2003) Monitoring vegetation phenology using MODIS. Remote Sens Environ 84:471-475

Zhang X, Friedl MA, Schaaf CB (2006) Global vegetation phenology from Moderate Resolution Imaging Spectroradiometer (MODIS): evaluation of global patterns and comparison with in situ measurements. J Geophys Res 111:G04017, doi:10.1029/2006JG000217 